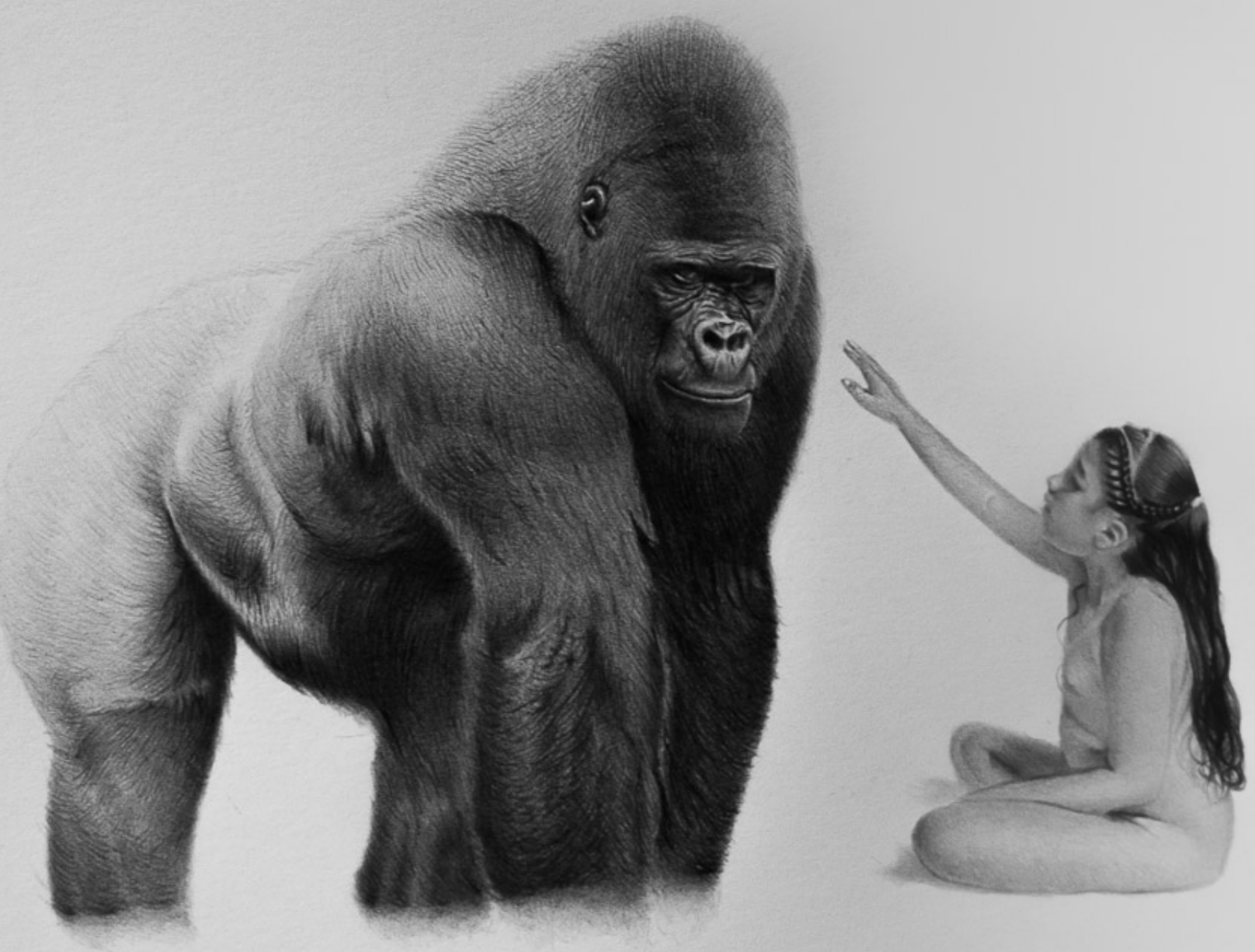

Sin título

De la serie Un viaje hacía el origen

Grafito sobre papel

$35 \times 50 \mathrm{~cm}$

2019

Medellí 


\title{
Discursos paralelos, pero en sentido opuesto. Análisis de los populismos de Jair Bolsonaro y Andrés Manuel López Obrador
}

\author{
Azucena Carolina Serrano Rodríguez (México**
}

\section{Resumen}

El presente artículo tiene como finalidad explicar por qué en las elecciones de 2018 en México y Brasil surgieron dos tipos diferentes de populismo si las dos naciones comparten un entorno político y económico semejante -corrupción, altos niveles de violencia, impunidad, desigualdad y pobreza-. El argumento central es que el discurso populista tuvo éxito en México y Brasil por cuatro factores: i) porque hubo una ruptura del orden social y los ciudadanos perdieron la confianza hacia las instituciones y en su capacidad para restaurarlo; ii) por el desprestigio que sufrió la clase política; iii) por las transformaciones que sufrieron los medios de comunicación masiva, los cuales facilitaron la difusión de mensajes populistas; y iv) por la parálisis de los partidos tradicionales. Sin embargo, en este artículo se sostiene que en México apareció un populismo de izquierda moderado y en Brasil uno de derecha radical debido a que el primer país mantenía un capitalismo excluyente y el segundo uno incluyente.

\section{Palabras clave}

Populismo; Política Comparada; Análisis de Discurso; Brasil; México.

Fecha de recepción: febrero de 2019 • Fecha de aprobación: junio de 2019

\section{Cómo citar este artículo}

Serrano Rodríguez, Azucena Carolina. (2019). Discursos paralelos, pero en sentido opuesto. Análisis de los populismos de Jair Bolsonaro y Andrés Manuel López Obrador. Estudios Políticos (Universidad de Antioquia), 56, pp. 149-173. DOI: 10.17533/udea.espo.n56a07

\footnotetext{
* Licenciada en Ciencias Políticas y Administración Pública. Magíster en Políticas Públicas. Magíster en Estudios Latinoamericanos. Correo electrónico: azucenacsr7@gmail.com
} 


\title{
Parallel Discourses, but in the Opposite Direction. Analysis of the Populisms of Jair Bolsonaro and Andrés Manuel López Obrador
}

\begin{abstract}
The purpose of this article is to explain why two different types of populism emerged in the 2018 elections of Mexico and Brazil, although both nations share a similar political and economic context (corruption, high levels of violence, impunity, inequality, poverty). The analysis shows that the populist discourse was successful both in Mexico and Brazil due to these four factors: i) there was a rupture in the social order, as a result, the citizens lost confidence in the institutions and in their capacity to restore this order; ii) the discredit suffered by the political class; iii) the transformations suffered by the mass media, which facilitated the dissemination of populist messages; and iv) the paralyses of the traditional parties. However, it is argued that the difference between both countries is that in Mexico there was a moderate left populism, founded on an exclusive capitalism, whereas in Brazil there was a radical right populism based on an inclusive capitalism.
\end{abstract}

\section{Keywords}

[150] Populism; Comparative Politics; Discourse Analysis; Brazil; Mexico. 


\section{Introducción}

En los últimos años se ha visto un aumento en la aparición de líderes populistas en el mundo, esto ha ocasionado que varios académicos de las ciencias sociales otorguen un gran interés al estudio de este fenómeno político, intentando responder qué factores están fomentando el surgimiento de los discursos populistas, cómo se manifiestan en cada país, qué efectos producen sobre las democracias liberales, entre otros.

En este artículo se busca responder a la pregunta de por qué pueden surgir diferentes tipos de populismo en contextos sociopolíticos y económicos similares. Para ello se abordan los casos de Brasil y México, en donde dos líderes populistas, Andrés Manuel López Obrador y Jair Bolsonaro, ganaron en 2018 las elecciones presidenciales de sus respectivos países. Hay que destacar que Brasil y México comparten los mismos problemas: pobreza, desigualdad, violencia, informalidad, alto grado de corrupción, entre otros, sin embargo, en los dos surgió un populismo diferente. Mientras que en México ganó un líder populista de izquierda e inclusivo, en Brasil se posicionó uno de ultraderecha y excluyente. ¿A qué se debió esta situación?

Se han elegido estos dos casos ya que los dos países cuentan con características políticas y económicas semejantes —desarrollo económico parecido, diseño institucional similar, entorno cultural análogo-, lo cual hace más viable la comparación; asimismo, porque ambos líderes ganaron en el mismo espacio temporal. Se utilizó el método cualitativo, es decir, a través de la revisión de fuentes primarias y secundarias de información, se hizo un análisis del discurso populista de los dos actores y, posteriormente, se plasmaron las reflexiones. Sin embargo, es menester aclarar que, dado el poco tiempo en ejercicio de ambos presidentes, únicamente se analizará el discurso que mantuvieron durante las campañas electorales.

\section{El concepto de populismo y problemas para definirlo}

Actualmente, en la ciencia política existe un amplio debate en torno al concepto de populismo. No hay un acuerdo sobre cómo definirlo (Mudde, 2017 , p. 1). Esto se debe a varias razones: primero, a la dificultad que existe para construir una definición que sea aplicable a cualquier contexto, época o región, ya que la mayoría de las definiciones que existen fueron elaboradas para explicar el fenómeno en el continente americano, lugar de origen del 
populismo; sin embargo, cuando dichos conceptos son utilizados en otras regiones quedan muy desfasados o inadecuados, por consiguiente, es difícil construir una definición que pueda adaptarse a cualquier entorno o país.

Las diferentes reacciones que suele causar el populismo también generan una falta de acuerdo en el concepto. Por una parte, existe una corriente de intelectuales (Di Tella, 1977; Bartra, 2008; Rosanvallon, 2008) que observan al populismo de manera despectiva. Lo ven como una amenaza hacia el régimen democrático liberal y hacia la protección de los derechos humanos de las minorías. Por otra parte, hay algunos académicos que sostienen una posición más neutral (Arditi, 2004; Panizza, 2005; Canovan, 1999; Laclau, 1977) y creen que el populismo es una luz roja que se enciende para advertir que la democracia liberal no está funcionando de manera adecuada o, al menos, no está cumpliendo con las expectativas que los ciudadanos tienen sobre ella. En este sentido, el populismo aparece como una oportunidad para reflexionar sobre las fallas que está teniendo el régimen democrático. Como sea, estas dos reacciones que produce el populismo hacen difícil el consenso en el concepto.

Finalmente, la tercera explicación de por qué hay tanto debate en torno [152] a la definición se refiere a que el populismo es un fenómeno polifacético, es decir, que se puede presentar de varias maneras. A pesar de que el populismo ha aparecido en muchas partes del mundo, su comparación resulta engorrosa porque cada uno tiene características propias. No es lo mismo el populismo de ultraderecha de Donald Trump en Estados Unidos que el de izquierda de Podemos en España. Sus discursos y formas de actuar son totalmente diferentes. Por tanto, esta variación hace muy difícil extraer los elementos esenciales del fenómeno.

Dada la dificultad de construir una definición consensuada sobre populismo, existen cuatro enfoques diferentes para aproximarse a él (Mudde, 2017): el primero de ellos es el enfoque discursivo, cuyo máximo exponente es Ernesto Laclau, y se centra en el discurso utilizado por los líderes populistas y observa a este fenómeno como una estrategia política para maximizar el apoyo popular; el segundo enfoque es el organizacional, propuesto por Kurt Weyland, el cual acentúa la relación que guarda el protagonista con el pueblo, en este sentido, el populismo se ve como un tipo particular de movilización popular, en donde los líderes se relacionan directamente con 
sus seguidores; el tercer enfoque es el cultural de Pierre Ostiguy, el cual focaliza su atención en el vocabulario y liderazgo utilizado por el líder, en esta perspectiva los populistas son aquellos que mantienen un liderazgo extremadamente personalista y utilizan un lenguaje popular; finalmente, el enfoque ideacional, el más extendido y usado por la academia, en el que se destacan Cas Mudde y Cristóbal Rovira (2013), trata al populismo como una ideología e intenta extraer sus elementos esenciales para así construir un concepto universal que permita el análisis comparativo. En el presente análisis se empleará este último enfoque, ya que es el más difundido en la academia; además, porque permite realizar un examen comparativo entre México y Brasil.

De acuerdo con el enfoque ideacional, el populismo es «una ideología delgada, que considera que la sociedad está dividida en dos grupos homogéneos y antagónicos, "el pueblo puro" contra la "élite corrupta", y que argumenta que las políticas deben ser una expresión de la voluntad general del pueblo» (Mudde, 2004).

Siguiendo a Mudde (2017), en esta definición se pueden identificar cuatro elementos clave: el primero se refiere a la noción de «ideología delgada», en el cual el populismo es considerado como una ideología delgada o menos elaborada porque otorga a los protagonistas la flexibilidad de enriquecer sus ideas con otras ideologías más sustantivas como el liberalismo, el nacionalismo o el socialismo. En este sentido, el populismo tiene ideas centrales -la distinción élite-pueblo y la voluntad general como guía para la toma de decisiones-, pero al mismo tiempo convive con otras ideologías más definidas, de ahí adquiere su carácter polifacético.

El segundo y tercer elemento tienen que ver con la creencia de cómo opera la política, es decir, con el enfrentamiento entre el pueblo y la élite. Para el fenómeno en cuestión, la política es concebida como una lucha entre dos fuerzas antagónicas: una buena, la cual está representada por el pueblo puro, casto y sabio; y otra mala y tenebrosa, la cual es una élite corrupta que ha abusado de su poder para obtener privilegios a costa del bienestar del pueblo. Esta oposición está fundamentada en una división moral (Mudde, 2017), donde el populista, basado en el imaginario colectivo, decide quiénes han actuado «bien» y pertenecen al pueblo puro y casto, y quiénes han actuado contra el pueblo y están dentro de la élite corrupta. 
El cuarto y último elemento clave que compone al concepto es la importancia de la apelación a la voluntad del pueblo. Muchos académicos han ignorado este elemento, sin embargo, resulta clave para la conceptualización del término, ya que el populismo no solo se trata de la distinción entre el pueblo y la élite, sino que además tiene que ver con la idea de que todos los individuos de una comunidad dada son capaces de unificar sus deseos con el objetivo de proclamar la soberanía popular como la única fuente legítima de poder político. Esto es posible debido a que el populismo concibe al pueblo como un grupo homogéneo capaz de distinguir lo que es bueno para el conjunto de la sociedad.

Ahora bien, este enfoque ideacional es muy útil porque presenta cuatro características que no están presentes en los otros enfoques (Mudde, 2017), las cuales son: transportabilidad, categorizabilidad, versatilidad y distinguibilidad.

En primer lugar, la definición ideacional, al contar con elementos básicos y no limitarse únicamente a una característica del populismo - como lo hacen los otros enfoques-, es transportable, es decir, se puede utilizar en cualquier contexto, época o región, lo cual facilita la realización de

[154] análisis comparativos; en segundo lugar, dado que considera al populismo como una ideología delgada que se complementa con otras ideologías más sustanciosas, el concepto ideacional es categorizable, esto es, posibilita crear subtipos de populismo y así realizar análisis más profundos; en tercer lugar, la definición de la perspectiva ideacional es distinguible porque permite diferenciar al populismo de otros fenómenos similares o de actores que se dicen ser populistas cuando no lo son; finalmente, el enfoque ideacional es versátil, puede aplicarse a un número amplio de actores como movimientos, partidos o regímenes políticos y, así, hacer estudios con un universo amplio de actores.

\section{Los subtipos de populismo}

Como se ha mencionado, al convivir su discurso con otro tipo de ideologías, el populismo adquiere un carácter polifacético, lo cual permite crear subtipos del fenómeno. En este artículo se utiliza la clasificación propuesta por Cas Mudde y Cristóbal Rovira (2013), aunque se agrega un elemento más a las categorías propuestas. 
Mudde y Rovira sugieren una categorización tomando en cuenta el carácter inclusivo-exclusivo del discurso, el cual se refiere a qué tan inclusivo o exclusivo es el discurso en su dimensión simbólica y política. Si el discurso del actor excluye a ciertos grupos —como minorías étnicas- de derechos políticos o de la categorización del pueblo, entonces se trata de un discurso excluyente. Cuando en el discurso todos los grupos -excepto la élite- son incluidos dentro del pueblo, e incluso se hace una reivindicación de los sectores que históricamente han sido marginados, entonces se trata de populismo incluyente.

Además de este elemento, en este ensayo se añadirá un componente más, el cual se refiere a la postura económica del protagonista. Los populistas que respaldan la existencia de un Estado interventor fuerte en la economía son considerados de izquierda, mientras que los que defienden un Estado con poca participación en el mercado son de derecha. Considerando estos dos elementos, se tienen los siguientes subtipos de populismo: populismos radicales de izquierda, populismos moderados de izquierda, populismos de derecha moderados y populismos radicales de derecha (véase cuadro 1).

Cuadro 1. Tipos de populismo.

\begin{tabular}{|l|l|l|l|l|}
\hline \multicolumn{1}{|c|}{ Características } & $\begin{array}{l}\text { Populismos } \\
\text { radicales de } \\
\text { izquierda }\end{array}$ & $\begin{array}{l}\text { Populismos } \\
\text { moderados de } \\
\text { izquierda }\end{array}$ & $\begin{array}{l}\text { Populismos } \\
\text { moderados de } \\
\text { derecha }\end{array}$ & $\begin{array}{c}\text { Populismos } \\
\text { radicales de } \\
\text { derecha }\end{array}$ \\
\hline Incluyentes/excluyentes & Incluyentes & Incluyentes & Incluyentes & Excluyentes \\
\hline $\begin{array}{l}\text { Libre mercado/Estado } \\
\text { interventor }\end{array}$ & $\begin{array}{l}\text { Estado } \\
\text { interventor } \\
\text { fuerte }\end{array}$ & $\begin{array}{l}\text { Estado } \\
\text { interventor } \\
\text { moderado }\end{array}$ & Libre mercado & Libre mercado \\
\hline Ejemplos & $\begin{array}{l}\text { Evo Morales } \\
\text { Hugo Chávez }\end{array}$ & $\begin{array}{l}\text { Podemos } \\
\text { (España) }\end{array}$ & $\begin{array}{l}\text { Alberto } \\
\text { Fujimori } \\
\text { Carlos Ménem }\end{array}$ & $\begin{array}{l}\text { Donald Trump } \\
\text { Marine Le Pen }\end{array}$ \\
\hline
\end{tabular}

Fuente: elaboración propia.

Como se verá más adelante, el populismo de Andrés Manuel López Obrador está situado en los de izquierda moderados, mientras que el de Jair Bolsonaro se encuentra en los radicales de derecha. Se verá que las 
condiciones económicas, políticas y sociales en las que triunfó el populismo tanto en México como en Brasil eran muy similares, sin embargo, en los dos surgieron diferentes tipos de populismo. Es por eso que se indaga a qué se debe esta situación, pues no basta con clasificar a los populismos, sino entender qué factores hacen que surjan diferentes subtipos.

\section{El triunfo del populismo en Brasil y México}

Antes de pasar a las comparaciones entre los casos de estudio, es preciso comentar quiénes son Andrés Manuel López Obrador y Jair Bolsonaro, y qué pasó en las elecciones presidenciales de sus respectivos países en las que ambos resultaron ganadores.

Jair Bolsonaro es un exmilitar que entró a la Cámara de Diputados de Brasil en la década de 1990, donde permaneció hasta 2018 cuando se presentó como candidato a la Presidencia, lo que le otorga un notable grado de antigüedad en el sistema político brasileño. «Si bien su rendimiento legislativo fue mediocre, fue el diputado que más votos recibió en las dos últimas elecciones legislativas en las que participó» (Alcántara, 2018, octubre 28). Cabe añadir que siempre se ha erguido como el representante

[156] de los sectores más conservadores y nostálgicos de la dictadura militar que gobernó Brasil entre 1964 y 1985. En las elecciones de 2018, después de que Lula Da Silva fue sentenciado a prisión por casos de corrupción, Bolsonaro se posicionó como el candidato favorito para la Presidencia de Brasil. Durante la campaña electoral fue apuñalado en el abdomen, lo cual le generó más seguidores. Fue así como ganó en la segunda vuelta electoral con $55 \%$ de los votos. Con esto, los partidos que tuvieron importancia en el pasado quedaron en una situación de cierta irrelevancia.

Por su parte, Andrés Manuel López Obrador es un hombre que no le apostó al dinero ni a los títulos académicos para alcanzar la Presidencia de México, sino a la perseverancia y a la astucia política. López Obrador ingresó a la política en 1976, cuando se afilió al Partido Revolucionario Institucional (PRI), salió de este en 1988 para afiliarse al recién creado Partido de la Revolución Democrática (PRD), de ahí fungió como presidente del partido y en 2000 fue electo como jefe de Gobierno de la Ciudad de México: «Luego fue candidato presidencial "permanente" desde 2006, dos veces con el PRD y una con MORENA, una corriente interna de aquel 
conformada en 2011 y que luego le sirvió como colchón para abandonar el PRD» (Alcántara, 2018, octubre 28). Nunca ha reconocido las elecciones presidenciales mexicanas de 2006 ni de 2012, las cuales califica de fraudulentas. Fue el candidato más votado en las elecciones mexicanas de 2018, al obtener 53\% de los votos. De hecho, ha sido el presidente mexicano que más votos ha recibido desde 1988. Cabe destacar que su partido político, Movimiento Regeneración Nacional (Morena), también consiguió arrasar en las votaciones, al conseguir la mayoría en las Cámaras de Diputados y de Senadores, y en varios Congresos locales, además de que los tres partidos tradicionales en México —Partido Acción Nacional (PAN), Partido Revolucionario Institucional (PRI) y Partido de la Revolución Democrática (PRD) - quedaron en una marginalidad sorprendente.

Ahora bien, es preciso cuestionar si es posible considerar como populista el discurso y la política que mantuvieron López Obrador y Bolsonaro en la campaña presidencial. Si se toma la definición dada en los apartados anteriores, se puede responder afirmativamente. En efecto, el populismo es una ideología delgada y central, que divide a la sociedad en dos grupos homogéneos y antagónicos: el pueblo y la élite. En cualquier discurso que se tome de López Obrador o de Bolsonaro, es posible encontrar esta división. Los dos líderes polarizan radicalmente a la sociedad y crean un «ellos»y un «nosotros».

Pero no solo eso, los dos apelan a la voluntad general como guía en la toma de decisiones. Durante toda su campaña, López Obrador insistió en que el pueblo mexicano es quien decidiría el rumbo del país a través de referéndums y consultas populares. Incluso antes de tomar posesión como presidente, el líder de origen tabasqueño realizó una "consulta popular» para decidir dónde se construiría el nuevo aeropuerto de la Ciudad de México. Por su parte, en los discursos de Bolsonaro también se encuentra la apelación de la soberanía del pueblo brasileño. Por ejemplo, en un mensaje de Twitter expresó: «iEstamos iniciando la última semana de camino a, si Dios quiere, nuestra nueva Independencia! ¡Vamos a tomar Brasil y devolvérsela a los brasileños!» (Bolsonaro, 2018, octubre 22). ${ }^{1}$

\footnotetext{
${ }^{1}$ La traducción de los tuiteos de Bolsonaro es propia.
} 


\section{Contexto del triunfo del populismo en Brasil y México}

Existen varios factores que favorecen el surgimiento de discursos populistas en los sistemas políticos y sus variables pueden ser tanto estructurales como individuales (Hawkins, Read \& Pauwels, 2017). Este artículo se focaliza en las primeras variables, sin embargo, no se desestima la importancia del ámbito individual.

Los factores estructurales más consensuados en el mundo académico son los sugeridos por Francisco Panizza (2005) y por Kirk Hawkins, Madeleine Read y Teun Pauwels (2017), los cuales son: i) la ruptura del orden social y la pérdida de confianza en la capacidad del sistema para restaurarlo; ii) el agotamiento de las tradiciones políticas y el desprestigio de los partidos políticos; iii) transformaciones en los medios de comunicación masiva; y iv) la parálisis del sistema de partidos. En este sentido, a continuación se explica cada variable aplicándolas a los casos de Brasil y México.

\subsection{Ruptura del orden social y la pérdida de confianza en las instituciones}

[158] De acuerdo con Panizza (2005), las crisis políticas, económicas y sociales que surgen en un sistema político y la falta de confianza en la capacidad de las instituciones para restablecer el orden abren las puertas para la aparición de populismos. Así, cuando en un Estado se manifiestan fenómenos que desestabilizan a la sociedad, como la hiperinflación, desempleo masivo, un ataque terrorista, una ola migratoria, escala de violencia, un conflicto étnico, entre otros, y además de ello, la sociedad percibe que las instituciones existentes están superadas por los problemas y son incapaces para responder a ellos, entonces se abren espacios para la emergencia de discursos mesiánicos y populistas. En México y Brasil se presenciaron este tipo de situaciones y por eso fue fácil que los discursos populistas y mesiánicos de López Obrador y Bolsonaro cobraran fuerza. Estos son los problemas que se presentaron y que rompieron con el orden social:

- Escala de violencia. En la última década, ambos países han presentado un aumento de la inseguridad en las calles. México llegó a registrar el año más violento en dos décadas con más de 65 asesinatos diarios (Excelsior, 2018, septiembre 22). Por su parte, Brasil también rompió récord en 
homicidios, registrando 175 muertes diarias en 2017 (Darlington, 2018). Salir a la calle resulta riesgoso por el nivel de violencia que abunda en los dos países.

- Impunidad. Otra de las situaciones que ha roto con el orden social en México y Brasil es la impunidad que impera en la sociedad. El Índice Global de Impunidad sitúa a Brasil entre los países más impunes. Con base en este índice, de 69 países, Brasil ocupa la séptima posición entre aquellos con mayor nivel de impunidad (Ferreira Do Vale, 2017, p. 110). México tiene cifras más escalofriantes: $99 \%$ de los delitos cometidos no son castigados (Milenio, 2016, febrero 3). El promedio son cinco condenas por cada cien víctimas, muy por debajo de las estadísticas del continente americano -24 sentencias-, de Asia -48 sentencias- o de Europa -80 sentencias por cada cien homicidios- (Ángel, 2018, julio $11)$.

- Corrupción. Las elecciones que presenciaron el ascenso de dos líderes populistas también se enmarcaron en escenarios similares de amplia corrupción. De hecho, ha sido señalado por muchos analistas como uno de los principales problemas de esos países, al impedir la inversión y bloquear el crecimiento económico (El Espectador, 2018, noviembre 13). Si bien el problema se ha manejado de diferente manera en los dos países, ya que en Brasil decenas de ex altos cargos del Ejecutivo y del Legislativo fueron encarcelados por corrupción, y en México solo un puñado de gobernadores recibió un castigo (Alcántara, 2018, octubre 28), es verdad que, en general, en la sociedad brasileña y mexicana se percibe un alto grado de corrupción, ya que de acuerdo con el Índice de Transparencia Internacional Brasil ocupa el número 105 y México el 138 de entre 180 países (Transparency International, 2018).

- Crisis económica. Otra situación que ha causado mucha desestabilización política y social es las crisis económicas que ambos países padecieron, manifestadas en inflación, aumento de la deuda pública, reducción del gasto privado, pérdida del poder adquisitivo y aumento de la desigualdad y la pobreza. Por ejemplo, Brasil sufrió durante dos años consecutivos -2015 y 2016 - la reducción de 3,5\% de su Producto Interno Bruto (PIB), es decir, en dos años su PIB tuvo un declive del más de $7 \%$; asimismo, la deuda interna ascendió a $65 \%$ del PIB, siendo la más alta de 
América Latina. De hecho, se considera que Brasil atravesó la peor crisis económica de los últimos cien años (Krugman, 2018, noviembre 12). En México las cosas no fueron mejores, en 2017 registró la inflación más alta en diecisiete años, al cerrar en 6,77\% (Pérez, 2017, julio 7). El peso mexicano se depreció ante el dólar hasta llegar a 23 pesos mexicanos, en comparación con 2012, cuyo valor fue de 13 pesos mexicanos; además, el poder adquisitivo ha caído 80\% en treinta años, pues en 1980 bastaban cuatro horas de trabajo para alimentar una familia de cuatro integrantes, mientras que ahora se requiere trabajar más de veinticuatro horas para comprar la misma cantidad de alimentos (Hernández, 2018, enero 15).

En resumen, tanto la escala de violencia, como la corrupción, la impunidad y las dificultades económicas rompieron con el orden social y crearon un sentimiento de angustia e inseguridad en las personas. Además, los ciudadanos percibieron al gobierno superado por los problemas existentes, no creyeron en la capacidad de las instituciones para resolver estas situaciones, lo cual provocó que el discurso populista, aquel que divide a la población en dos y achaca todos los problemas del país a una élite corrupta, hiciera eco en el electorado.

\subsection{El desprestigio de la clase política}

El segundo factor que favorece la aparición de populismos es el agotamiento de las tradiciones políticas y el desprestigio de los partidos políticos. Tanto en México como en Brasil los casos de corrupción del Gobierno que se ventilaron en los medios de comunicación hicieron perder la confianza de los ciudadanos hacia toda la élite política.

En Brasil, el caso Odebrecht, la destitución de Dilma Rousseff y el encarcelamiento de varios funcionarios públicos por casos de corrupción causaron mucha repugnancia en los ciudadanos, llegando a recelar del gobierno y de los partidos políticos. Lo anterior se comprueba si observa la confianza que los brasileños tienen hacia los partidos políticos, el cual es de 7\% (Latinobarómetro, 2017). Por su parte, la "Casa Blanca" en México, la estafa maestra, el caso Duarte y Oceanografía provocaron en los mexicanos un sentimiento de malestar y hartazgo hacia la clase política. De hecho, solo 9\% de los mexicanos siente confianza hacia el Gobierno (Latinobarómetro, 2017). Además, la mayoría de los problemas, como la crisis económica y la 
escala de violencia, son vistos en ambos países como una consecuencia de las malas políticas ejecutadas por los gobiernos.

Para las dos sociedades todos los partidos y miembros de la élite son parte del problema. En este sentido, era de esperarse que un líder que se proclamó outsider del sistema y que culpó al Gobierno y a la élite de todos los males, lograra cooptar el apoyo de los electores.

\subsection{Transformaciones en los medios de comunicación masiva}

El tercer factor que favorece el triunfo del populismo es el de las transformaciones en los medios de comunicación masiva (Panizza, 2005). La aparición de las redes sociales ha promovido el surgimiento y la expansión de discursos populistas. Esto se debe a tres situaciones: primero, la facilidad que las redes tienen para difundir mensajes políticos de manera directa, ya que no se requiere pagar o acudir a alguna empresa televisiva o radiofónica para expresar ideas; segundo, la difusión que pueden alcanzar algunos mensajes, debido a que solo se necesita un clic para difundir un discurso que puede volverse viral en tan solo unos segundos y llegar a un gran número de personas, contribuyendo a la configuración de la opinión pública; y tercero, la dificultad que existe para controlar esos mensajes, los cuales muchas veces pueden estar manipulados.

Si bien la campaña electoral de López Obrador se basó más en el recorrido que hizo por todo el país, mientras que Bolsonaro fue más activo en redes sociales después de ser apuñalado en campaña (Alcántara, 2018, octubre 28), es verdad que tanto Facebook, como Twitter, WhatsApp e Instagram fueron un poderoso vehículo para que ambos candidatos pudieran propagar sus políticas populistas y ganar más adeptos.

En el caso de Bolsonaro, hay que mencionar, en primer lugar, que los electores del exmilitar tuvieron el índice más alto de usuarios de alguna red social $-81 \%$ contra $59 \%$ de Fernando Haddad—; además, fue el aspirante con más seguidores en las redes sociales, unos 10,5 millones, con un aumento de $41 \%$ entre enero y agosto de 2018 (El Universal, 2018, octubre 5): «Bolsonaro no contó con el apoyo de la prensa tradicional, la campaña la realizó a través de las redes sociales, del WhatsApp» (Ramos, 2018). En el caso de López 
Obrador, en los primeros veintidós días de campaña fue quien sumó más seguidores en sus cuentas de redes sociales, con un crecimiento de $40 \%$ en Facebook, 54\% en Twitter y 27\% en Instagram (Durán, 2018, abril 21).

Por esas razones, las transformaciones en los medios de comunicación masiva, específicamente la aparición y el uso masificado de las redes sociales, han sido un factor que ha facilitado la emergencia de discursos populistas. En el caso de Brasil y México, fueron clave para que López Obrador y Bolsonaro pudieran difundir sus ideas y así ganar adeptos entre los electores.

\subsection{Parálisis del sistema de partidos}

Sin embargo, la corrupción, el desgaste de la clase política y la aparición de nuevos medios de comunicación no son elementos suficientes para que el populismo logre triunfar en las elecciones, también se debe tomar en cuenta la estructura de oportunidades políticas, es decir, la forma en que los partidos tradicionales responden y hacen frente al discurso populista y a las demandas del electorado (Hawkins, Read y Pauwels, 2017, p. 278). Si los partidos opositores consiguen reformular su programa de acción y atienden a las exigencias de los ciudadanos, existen amplias posibilidades de que

[162] estos partidos puedan frenar el apoyo populista; sin embargo, si no logran transformarse ante el electorado, las probabilidades del triunfo electoral del populismo son altísimas.

Tanto en Brasil como en México los ciudadanos estaban enojados e irritados por el contexto de violencia, desempleo y corrupción y exigían soluciones a estos problemas; pues solo el $13 \%$ de los brasileños y $18 \%$ de los mexicanos estaba satisfecho con el funcionamiento de la democracia (Latinobarómetro, 2017). Sin embargo, por distintas razones, los partidos políticos tradicionales no atendieron estas demandas, lo cual fue aprovechado por los líderes populistas.

En México, los tres partidos más influyentes descuidaron a los votantes, sin atender sus deseos. El PRI hizo caso omiso de las acusaciones de corrupción contra los integrantes del partido (Villamil, 2018, enero 24); el PAN, además de fracturarse por la candidatura a la presidencia, se enfrascó en una lucha contra la cúpula del PRI por acusaciones de corrupción que la Procuraduría General de la República había hecho contra Ricardo Anaya, el candidato a la presidencia del PAN, lo cual hizo que el partido descuidara 
al electorado mexicano (Nakamura, 2018, Julio 1. ${ }^{\circ}$ ); y el PRD hizo a un lado sus ideales progresistas y se alió con el PAN — partido conservador-para obtener más votos, lo cual fue visto como una ambición sin límite por varios votantes (Alemán, 2018, julio 10). Todo esto benefició a López Obrador, quien tuvo una competencia sin estorbo de los partidos tradicionales.

En Brasil, los partidos no pudieron responder a las demandas de los brasileños ya que no lograron recuperarse de los efectos colaterales de la operación Lava Jato. En efecto:

Esta operación (cuyo principal blanco siempre fue el PT), atacó a todos los partidos que formaron parte del juego político desde el restablecimiento de la democracia a fines de la década de 1980. Los escándalos de corrupción alcanzaron al PT, al PSDB, el Partido del Movimiento Democrático Brasileño, a Demócratas (ex Partido del Frente Liberal, el partido conservador más tradicional) y a muchos de los partidos del centro pragmático, y produjeron un descrédito generalizado en la población (Berrón, 2018, octubre).

Sin embargo, estos partidos nunca consiguieron recuperarse de estos efectos negativos, lo cual favoreció a Bolsonaro, quien logró despegarse de esta clase política, haciéndose pasar por un outsider del sistema (Berrón, 2018, octubre).

Por tanto, la parálisis política de los partidos tradicionales en Brasil y el descuido que el PRI, PAN y PRD tuvieron hacia el electorado mexicano fue aprovechado eficazmente por Jair Bolsonaro y Andrés Manuel López Obrador, quienes con sus discursos dirigieron la ira de los votantes hacia la élite política tradicional y ofrecieron respuestas alternativas a los problemas del país, ganándose, de esta forma, a la mayoría del electorado y ocasionando el colapso del sistema de partidos en ambos países. Así, la falta de respuesta de los partidos tradicionales al electorado y a los problemas de los países logró el triunfo de los líderes populistas.

En síntesis, tanto la ruptura del orden y la pérdida de confianza hacia el Gobierno para restaurarlo, el desprestigio político de la clase política, las transformaciones en los medios de comunicación masiva y la parálisis de los partidos tradicionales permitieron el triunfo de los líderes populistas en México y Brasil. En ambos países el contexto fue muy similar: una crisis económica que estaba ahogando la economía de los hogares, una escala de 
violencia imparable, casos de corrupción que fueron procesados de manera ineficaz - hablando en términos políticos- y una falta de respuesta de los partidos tradicionales; sin embargo, en los dos países aparecieron diferentes subtipos de populismos: en México se desarrolló uno de izquierda y en Brasil uno de derecha.

\section{Andrés Manuel López Obrador y Jair Bolsonaro: dos populistas antagónicos}

De acuerdo con la clasificación que se expuso en el tercer apartado, hay dos elementos para comparar: el grado de inclusión y exclusión del discurso y las políticas económicas que proponen.

\subsection{Populismo incluyente-excluyente}

Este elemento se refiere a qué tan incluyente o excluyente es el protagonista en el proceso de nominación en el que se decide quiénes pertenecen al pueblo y quiénes a la «élite corrupta». En el caso de Bolsonaro, hay una construcción simbólica del pueblo constituida por los brasileños que se han sentido afectados por las políticas «socialistas» de los gobiernos anteriores. Esto se puede inferir con el siguiente tuiteo:

Nuestros ciudadanos están agotados de pagar impuestos y ver que su dinero está siendo usado para promover regímenes socialistas alrededor del mundo. Brasil ha sido rebajado por los peores escándalos de corrupción en la historia, llevados por la oposición y su líder quien, desde la cárcel, continúa dando órdenes. El pueblo brasileño no solo desea un cambio, sino que lo demanda (Bolsonaro, 2018, octubre 23).

De esto se deduce que los que conforman el pueblo brasileño son aquellos que están cansados del régimen anterior. En el imaginario de Bolsonaro, el pueblo es el que desea y demanda un cambio de gobierno, por lo tanto, todos los que apoyan a Lula Da Silva y al PT quedan excluidos de la categorización del pueblo.

Pero algunos grupos minoritarios también están excluidos, especialmente aquellos que, como dijo el propio Bolsonaro, «atentan contra la mayoría» y «las tradiciones judeo-cristianas» del pueblo brasileño. Por ejemplo, en 2017 dijo en conferencia de prensa: «Dios encima de todo. No quiero esa historia de Estado laico. El Estado es cristiano y la minoría que esté en contra, que se mude. Las minorías deben inclinarse ante las mayorías» 
(La Jornada, 2018, octubre 9). De tal forma, en el discurso de Bolsonaro las minorías son aquellas que no apoyan un «Estado cristiano», como pueden ser los movimientos feministas que abogan por el respeto y aceptación de distintos tipos de familias y no solo de la tradicional.

Cabe agregar que el discurso del nuevo presidente de Brasil también muestra desdén hacia los afrodescendientes, mujeres y migrantes. En una entrevista de televisión, cuando le preguntaron acerca de las acciones afirmativas hacia las mujeres, contestó: «No es una cuestión de colocar cupos de mujeres. Si ponen mujeres porque sí, van a tener que contratar negros también»(CNNChile, 2018, octubre 8).

En este sentido, el discurso populista de Bolsonaro es excluyente, ya que algunas minorías quedan fuera del proceso de nominación del pueblo. En su imaginario, el pueblo está conformado por los brasileños cristianos, de clase media o alta, los cuales han sido «víctimas» de las «políticas socialistas del PT». Sin embargo, Bolsonaro aclaró que arropa a aquel que esté «sujeto a nuestras leyes, reglas y costumbres, así como deberá cantar nuestro himno y respetar nuestra cultura» (El País, 2019, enero 9).

Por su parte, López Obrador se distingue por la construcción de un pueblo más plural, aunque no deja de ser excluyente. En este populismo el pueblo lo conforman todos los mexicanos, excepto "la mafia del poder», conformada por toda la «tecnocracia neoliberal» de los últimos gobiernos de México. Por ejemplo, en el manifiesto de su partido se lee lo siguiente:

Aquí participan mexicanos de todas las clases sociales y de diversas corrientes de pensamiento, religiones y culturas. En Morena, participan mujeres y hombres; empresarios, productores y consumidores; estudiantes y maestros; obreros, campesinos e indígenas. Estamos convencidos que sólo la unidad de todos los mexicanos hará posible la transformación del país (Morena, 2013a, p. 3).

Como podemos observar, este discurso es más incluyente, ya que en la conformación del pueblo no excluye a minorías. Los únicos excluidos de la categoría son la «mafia del poder» conformada por la «oligarquía mexicana junto con las cúpulas del PRI y el PAN que han impuesto por la vía de los hechos a través de elecciones fraudulentas, en su momento a Carlos Salinas de Gortari y recientemente a los gobiernos de Felipe Calderón y Enrique Peña Nieto» (Morena, 2013b, p. 1). 
En resumen, los dos populismos difieren en su dimensión simbólica y política, ya que el discurso de López Obrador es más incluyente, mientras que el de Jair Bolsonaro excluye a las minorías, las cuales deja por fuera del conjunto del pueblo.

\subsection{Políticas económicas}

Respecto a las políticas económicas anunciadas por los dos líderes populistas, ambos defienden un modelo económico contrapuesto. Mientras que Bolsonaro apoya una economía liberal, López Obrador busca desarrollar una de estilo keynesiano.

En efecto, Bolsonaro no solo ha nombrado a personas con pensamiento liberal en su gabinete como Paulo Guedes, egresado de la Universidad de Chicago -institución de referencia del pensamiento económico liberaly cofundador del Instituto Milennium - think tank de expertos liberales-, sino que también propuso durante su campaña varias políticas neoliberales, como: reducir la deuda pública a $20 \%$ mediante privatizaciones, concesiones y venta de propiedades públicas; implementar un régimen de pensiones de capitalización individual similar al chileno; liberar la explotación del

[166 ] petróleo a la manera estadounidense; y redistribuir la carga tributaria (San Román, 2018, octubre 29).

Por su parte, López Obrador defiende una economía totalmente diferente a la del brasileño. El tabasqueño busca crear un modelo económico keynesiano donde el Estado tenga mayor intervención en la economía nacional. En su programa político indica que se instaurará un nuevo modelo económico porque:

La crisis económica mundial revela el fracaso del modelo neoliberal que no ha sido capaz de brindar bienestar a los pueblos. [...] Por ello, es necesario transformar el modelo de desarrollo imperante, por uno [...] en donde el Estado asuma la responsabilidad de conducir el desarrollo sin injerencia externa. [...] Se luchará por poner fin a la privatización de Pemex, la industria eléctrica y del patrimonio cultural. Luchamos contra la entrega del territorio a empresas mineras que devastan el territorio, generan pobreza, no pagan impuestos y dañan el medio ambiente (Morena, 2013b, p. 6).

Como se observa, el populismo de López Obrador muestra una tendencia más intervencionista del Estado en la economía nacional. En 
su discurso busca transformar el modelo neoliberal por uno keynesiano. Esto también se comprueba con los miembros de su gabinete, quienes en su mayoría son personajes que defienden ideas económicas de izquierda, como son: Carlos Manuel Urzúa, María Luisa Albores, Jorge Alcocer Varela, entre otros.

De esta manera, se hayan dos tipos de populismos: el de Jair Bolsonaro, que se clasificaría como duro de derecha al mantener un discurso excluyente y una política económica neoliberal; y el populismo blando de izquierda de Andrés Manuel López Obrador, que promueve un discurso incluyente y una política económica keynesiana. Ahora bien, la pregunta que surge es por qué en los dos países aparecieron populismos divergentes cuando las condiciones que permitieron su triunfo eran similares.

\section{El surgimiento de los dos subtipos de populismo}

El ascenso de líderes, movimientos y partidos populistas con múltiples formas y expresiones ha causado que el mundo académico se pregunte sobre las condiciones sociales, políticas y económicas que originan distintos subtipos de populismo. Como consecuencia han surgido varias respuestas a este interrogante (Filc, 2015; Art, 2011; Padoan, 2016, 15-18 de junio). Sin embargo, la explicación que más esclarece por qué en México y Brasil surgieron diferentes tipos de populismo es la expuesta por Kenneth Roberts (2017), quien al realizar una comparación entre los populismos de Europa y de América Latina argumenta que «las formas más inclusivas de capitalismo pueden provocar variantes exclusivas o derechistas de populismo, mientras que las formas exclusivas de capitalismo son caldo de cultivo de subtipos inclusivos o izquierdistas de populismos» (pp. 235).

De acuerdo con Roberts (2017, p. 236), se pueden identificar dos tipos de capitalismos: aquellos que son más inclusivos, es decir, donde existen Estados de bienestar que ofrecen una amplia gama de beneficios universales y buscan la inclusión de todos los grupos dentro de la comunidad nacional _incluso los más marginados, como los migrantes o minorías étnicas-; y aquellos que son exclusivos, donde el Estado de bienestar es muy débil y cuenta con un mercado sumamente dualizado solo unos cuantos trabajadores disfrutan de seguridad social, mientras que otros están sumergidos en la informalidad-. 
Pues bien, los dos capitalismos impactan en los niveles de desigualdad y los diferentes grados de integración y segmentación social. En este sentido, el capitalismo inclusivo, aquel que otorga un gran número de programas sociales y busca reducir la desigualdad social, crea un grado de cohesión en la comunidad; sin embargo, en momentos de crisis políticas y económicas, aquellos que están en posiciones más aventajadas buscarán reducir el nivel de acción del Gobierno e intentarán delimitar las fronteras del «pueblo» para proteger sus intereses. Por esta razón, en los capitalismos inclusivos suelen surgir populismos excluyentes y de derecha.

Mientras que el capitalismo excluyente, aquel cuyo Estado de bienestar es débil y donde hay un mercado laboral dual, «crea distinciones básicas entre los ciudadanos que son incluidos y entre quienes son total o parcialmente excluidos de un empleo seguro y de todas las formas básicas de servicio social» (Roberts, 2017, p. 236). Esta exclusión de facto de un gran porcentaje de la comunidad nacional — un segmento que pertenece al pueblo- puede crear una afinidad optativa por las formas izquierdistas e inclusivas de movilización populista bajo condiciones de crisis e insuficiente representación partidaria.

La paradoja, entonces, es que las formas excluyentes de populismo pueden encontrar su suelo más fértil donde los mercados de trabajo capitalistas y los Estados de bienestar son más inclusivos, igualitarios e integradores, mientras que las formas inclusivas de populismo pueden arraigarse y prosperar donde el capitalismo es más excluyente, segmentado y dualista (Roberts, 2017, p. 237).

Desde inicios del siglo xxı, en Brasil y México se instauraron dos tipos de capitalismos: uno inclusivo y otro exclusivo, respectivamente. Si bien Brasil tiene graves desafíos en materia de desigualdad, pobreza e informalidad, es verdad que durante los últimos quince años el PT, liderado por Lula Da Silva, estableció un Estado benefactor que sacó a un significativo porcentaje de personas de la pobreza y que fomentó la inclusión social. Entre 2001 y 2003, los brasileños que viven con menos de 2,5 dólares al día cayó de $10 \%$ a $4 \%$; además, $60 \%$ de la población aumentó su nivel de renta en ese mismo periodo. En total, 25 millones de personas dejaron de vivir en la pobreza —extrema o moderada-. Esto se debió a las políticas públicas inclusivas implementadas por Lula que buscaron la erradicación de la pobreza, como Bolsa Familia o Brasil sin Miseria. Asimismo, hay que 
destacar que las tasas de empleo formal aumentaron $60 \%$ y un porcentaje considerable logró acceder a la clase media (El País, 2015, abril 23).

En Brasil se buscó construir un capitalismo inclusivo que fomentara la inclusión y cohesión social; sin embargo, en 2015, cuando el país entró en recesión, todos los grupos que de alguna forma lograron subir en la pirámide de estratificación social y los que ya ocupaban un lugar alto en ella presionaron al sistema para que fuera menos inclusivo y los pocos recursos con los que contaba el Estado se reservaran para ellos, es decir, se presionó al sistema para contar con una delimitación del pueblo menos incluyente. Es por eso que en este país el populismo exclusivo y derechista de Bolsonaro prosperó hasta obtener el triunfo.

En México ocurrió todo lo contrario. Desde la década de 1980 los gobiernos mexicanos consolidaron un Estado exclusivo e implementaron reformas neoliberales: privatización, desregulación, desnacionalización, flexibilidad laboral, entre otras. Existe un relativo consenso entre los economistas en que este modelo económico —o la forma ineficaz en que se implementó- aumentó la desigualdad, la pobreza, la informalidad, redujo el poder adquisitivo de las personas, profundizó las asimetrías entre las zonas rurales y urbanas, favoreció la creación de empleos de baja calidad y polarizó el ingreso, ocasionando un incremento en la marginalización (Méndez, 2015).

Ante esta situación y ante el aumento de la violencia, los sectores excluidos de este capitalismo - los cuales podrían representar más de 60\% de la población, si se cuentan a los que se encuentran en pobreza y en el sector informal- se movilizaron para crear una integración más profunda de la comunidad nacional, es decir, para superar los patrones de segmentación y dualización que impiden que el pueblo se constituya como un todo. Por esta razón es que el populismo inclusivo y de izquierda de López Obrador tuvo eco en México y ganó en las elecciones de 2018.

\section{Conclusiones}

Brasil y México experimentaron el ascenso de dos populismos antagónicos. Mientras Andrés Manuel López Obrador mantiene un discurso incluyente y una economía de estilo keynesiana, Jair Bolsonaro exhibe un discurso excluyente y promueve una economía neoliberal. 
Las condiciones en que surgieron fueron semejantes: escalada de la violencia, impunidad, crisis económica, corrupción, desprestigio de la clase política, uso de redes sociales y parálisis de los partidos tradicionales. Sin embargo, los brasileños optaron por votar a Jair Bolsonaro, un líder populista de derecha, mientras que los mexicanos prefirieron a Andrés Manuel López Obrador, el cual tiene una tendencia más izquierdista.

Esto se debió a que durante quince años Brasil mantuvo un capitalismo inclusivo y cuando el país entró en recesión los actores más favorecidos o que se vieron beneficiados por el Estado presionaron para que este se volviera excluyente. De esta forma se optó por un populismo duro de derecha. Por su parte, México impulsó un capitalismo excluyente durante más de treinta años, lo que provocó que los actores excluidos decidieran apoyar a un populista blando de izquierda para ser incluidos en los beneficios que el Gobierno otorga.

Si bien este solo fue un ejercicio exploratorio, faltan muchas preguntas por contestar, por ejemplo: ¿qué consecuencias tendrá la llegada de estos actores para la democracia de estos países?, ¿cómo será su gestión?, ¿cómo harán para que su discurso populista siga teniendo vigencia? En fin, todavía

[170] tenemos que hacer un gran recorrido para comprender de mejor manera el fenómeno populista.

\section{Referencias bibliográficas}

1. Alcántara, Manuel. (2018, octubre 28). Brasil y México, ¿vidas paralelas? Sí, pero en sentido opuesto. Estudios de Política Exterior. Recuperado de https://www. politicaexterior.com/latinoamerica-analisis/brasil-mexico-vidas-paralelas-sentidoopuesto/

2. Alemán, Ricardo. (2018, julio 10). PAN-PRD, fracaso cultural. La Otra Opinión. Recuperado de https://www.laotraopinion.com.mx/pan-prd-fracaso-cultural/

3. Ángel, Arturo. (2018, julio 11). La justicia en México es un desastre, ¿cómo reconstruirla? The New York Times. Recuperado de https://www.nytimes.com/ es/2018/07/11/opinion-arturo-angel-mexico-impunidad-crisis-justicia/

4. Arditi, Benjamín. (2004). Populism as a Spectre of Democracy: A Response to Canovan. Political Studies, 52 (1), pp. 135-143. DOI: 10.1111/j.14679248.2004.00468.x

5. Art, David. (2011). Inside the Radical Right: The Development of AntiImmigrant Parties in Western Europe. New York: Cambridge University. DOI: 10.1017/CBO9780511976254 
6. Bartra, Roger. (2008). Populismo y democracia en América Latina. Letras Libres, 10 (112), pp. 48-53.

7. Berrón, Gonzalo. (2018, octubre). Odio, frustración y valores reaccionarios. Jair Bolsonaro y la regresión política en Brasil. Nueva Sociedad. Recuperado de https:// nuso.org/articulo/odio-frustracion-y-valores-reaccionarios/

8. Bolsonaro, Jair. [@jairbolsonaro]. (2018, octubre 23). Trazemos mais verdades. [Actualización de estado de Twitter]. Recuperado de https://twitter.com/ jairbolsonaro/status/1054680169187819521

9. Bolsonaro, Jair. [@jairbolsonaro]. (2018, octubre 22). Estamos iniciando a última semana a camino, de, se Deus quiser, nossa nova Independéncia! Vamos tirar o Brasil do vermelho e devolvé-lo aos brasileiros!. [Actualización de estado de Twitter]. Recuperado de https://twitter.com/jairbolsonaro/status/1054350557090070531

10. Canovan, Margaret. (1999). Trust the People! Populism and the Two Faces of Democracy. Political Studies, 47(1), pp. 2-16. DOI: 10.1111/1467-9248.00184

11. CNNChile. (2018, octubre 8). "Sería incapaz de amar a un hijo homosexual»: 10 polémicas frases que retratan a Jai Bolsonaro. Recuperado de https://www.cnnchile. $\mathrm{com} / \mathrm{mundo} /$ seria-incapaz-de-amar-a-un-hijo-homosexual-10-polemicas-frases-queretratan-a-jair-bolsonaro_20181008/

12. Darlington, Shasta. (2018, agosto 15). Tras un año de violencia, Brasil rompe sus récords de homicidios. The New York Times. Recuperado de https://www.nytimes. com/es/2018/08/15/brasil-homicidios-record-violencia/

13. Di Tella, Torcuato. (1997). Populism into the Twenty-First Century. Government and Opposition, 32 (2), pp. 187-200. DOI: 10.1111/j.1477-7053.1997. tb00157.x

14. Durán, Leonardo. (2018, abril 21). AMLO, el candidato que más crece en redes sociales. El Universal. Recuperado de https://www.eluniversal.com.mx/ elecciones-2018/amlo-el-candidato-que-mas-crece-en-redes-sociales

15. El Espectador. (2018, noviembre 13). Economía, violencia y corrupción: los problemas de América Latina. Recuperado de https://www.elespectador.com/ noticias/el-mundo/economia-violencia-y-corrupcion-los-problemas-de-america-latinaarticulo-823375

16. El País. (2015, abril 23). Brasil lidera la reducción de la pobreza, según el Banco Mundial. Recuperado de https://elpais.com/internacional/2015/04/23/ actualidad/1429745195_504833.html

17. El País. (2019, enero 9). Brasil se retira del Pacto Migratorio de la ONU: «No cualquiera entra en nuestra casa». Recuperado de https://www.elpais.com.uy/mundo/ bolsonaro-anuncio-retiro-brasil-pacto-migratorio-onu.html

18. El Universal. (2018, octubre 5). Las redes sociales impulsan a Bolsonaro en Brasil. Recuperado de http://www.eluniversal.com/internacional/22363/las-redessociales-aupan-a-bolsonaro-en-brasil 
19. Excelsior. (2018, septiembre 22). Violencia en México genera 77 asesinatos al día. Recuperado de https://www.excelsior.com.mx/nacional/violencia-en-mexicogenera-77-asesinatos-al-dia/1266821

20. Ferreira Do Vale, Hélder. (2017). La impunidad en Brasil: causas y consecuencias Eunomía, 14, pp. 106-123. DOI: 10.20318/eunomia.2018.4158

21. Filc, Dani. (2015). Latin American Inclusive and European Exclusionary Populism: Colonialism as an Explanation. Journal of Political Ideologies. 20 (3), pp. 263-283. DOI: 10.1080/13569317.2015.1075264

22. Hawkins, Kirk; Read, Madeleine \& Pauwels, Teun. (2017). Populism and Its Causes. In: Rovira Kaltwasser, Cristóbal; Taggart, Paul; Ochoa Espejo, Paulina \& Ostiguy, Pierre (eds.). The Oxford Handbook of Populism. New York: Oxford University. DOI: 10.1093/oxfordhb/9780198803560.013.13

23. Hernández, Manuel. (2018, enero 15). Poder adquisitivo de los mexicanos cae en 30 años, revela la UNAM. The Huffington Post. Recuperado de https://www. huffingtonpost.com.mx/2018/01/15/poder-adquisitivo-de-los-mexicanos-cae-80-en30-anos-revela-la-unam_a_23333915/

24. Krugman, Paul. (2018, noviembre 12). ¿Qué demonios le pasó a Brasil?. The New York Times. Recuperado de https://www.nytimes.com/es/2018/11/12/paulkrugman-crisis-brasil/

25. Laclau, Ernesto. (1977). Politics and Ideology in Marxist Theory: Capitalism, Fascism, Populism. London: New Left.

[172] 26. La Jornada. (2018, octubre 9). «Estoy en favor de la tortura»... y otras frases del ganador. Recuperado de https://www.jornada.com.mx/2018/10/09/ mundo/029n2mun

27. Latinobarómetro. (2017). Informe 2017. Recuperado de http://www. latinobarometro.org/LATDocs/F00006433-InfLatinobarometro2017.pdf

28. Méndez, José Silvestre. (2015). El neoliberalismo en México ¿éxito o fracaso? Contaduría y Administración, 191, pp. 65-73.

29. Milenio. (2016, febrero 3). 99\% de delitos no se castigan en México, revela Índice de impunidad. Recuperado de http://www.milenio.com/politica/99-delitoscastigan-mexico-revela-indice-impunidad

30. Movimiento Regeneración Nacional (Morena). (2013a). Declaración de Principios de Morena. AMLO. Recuperado de https://lopezobrador.org.mx/wpcontent/uploads/2013/02/Declaracion-de-Principios-MORENA.pdf

31. Movimiento Regeneración Nacional (Morena). (2013b). Programa del Movimiento Regeneración de Nacional. ¿Por qué luchamos? AMLO. Recuperado de https://lopezobrador.org.mx/wp-content/uploads/2013/02/Programa-MORENA.pdf

32. Mudde, Cas. (2004). The Populist Zeitgeist. Government and Opposition, 39 (4), pp. 541-563. DOI: 10.1111/j.1477-7053.2004.00135.x 
33. Mudde, Cas. (2017). Populism: An Ideational Approach. En: Rovira Kaltwasser, Cristóbal; Taggart, Paul; Ochoa Espejo, Paulina \& Ostiguy, Pierre (eds.). The Oxford Handbook of Populism. New York: Oxford University. DOI: 10.1093/ oxfordhb/9780198803560.013.1

34. Mudde, Cas y Rovira, Cristóbal. (2013). Exclusionary vs. Inclusionary Populism: Comparing Contemporary Europe and Latin America. Government and Opposition, 48 (2), pp. 1-28. DOI: 10.1017/gov.2012.11

35. Panizza, Francisco (coord.). (2005). Populism and the Mirror of Democracy. London: Verso.

36. Padoan, Enrico. (2016, 15-18 June). A Latin Americanization of Southern Europe? A typology of Antineoliberal Turns in Dualized Societies. Standing Group on the European Union Conference. European Consortium for Political Research, University of Trento, Trento.

37. Pérez, D. M. (2017, julio 7). México registra la inflación más alta en 8 años. El País. Recuperado de https:/elpais.com/economia/2017/07/07/ actualidad/1499461545 726890.html

38. Ramos Garbiras, Alberto. (2018). Bolsonaro, el populismo de extrema derecha. Viva la Ciudadanía. Recuperado de http://viva.org.co/cajavirtual/svc0613/ pdfs/10_Bolsonaro_el_populismo_de_extrema_derecha.pdf

39. Rosanvallon, Pierre. (2008). Counter-Democracy: Politics in an Age of Distrust. Cambridge: Cambridge University. DOI: 10.1017/CBO9780511755835

40. San Román, Ignacio. (2018, octubre 29). Bolsonaro, una receta neoliberal para un país polarizado. Cinco Días. Recuperado de https://cincodias.elpais.com/ cincodias/2018/10/26/mercados/1540567158_063725.html

41. Transparency International. (2018). Corruption Perception Index 2018. Recuperado de https://www.transparency.org/cpi2018

42. Villamil, Jenaro. (2018, enero 24). El verdadero decálogo de la corrupción que Meade ignora. Proceso. Recuperado de https://www.proceso.com.mx/519825/ el-verdadero-decalogo-de-la-corrupcion-que-meade-ignora 